\title{
STUDY OF CORONARY OSTIA, THEIR VARIATIONS \& CLINICAL SIGNIFICANCE
}

Rupa Chhaparwal ${ }^{1}$, S. S. Joshi², S. D. Joshi ${ }^{3}$

\section{HOW TO CITE THIS ARTICLE:}

Rupa Chhaparwal, S. S. Joshi, S. D. Joshi. "Study of Coronary Ostia, Their Variations \& Clinical Significance". Journal of Evolution of Medical and Dental Sciences 2015; Vol. 4, Issue 85, October 22; Page: 14806-14816, DOI: $10.14260 /$ jemds/2015/2107

\begin{abstract}
Anomalies of the coronary ostia are of great practical significance than those of coronary arterial distribution. High degree of association exists between anomalies of the coronary ostia and other congenital cardiovascular defects. Detailed knowledge and awareness of the anatomical variations in ostia of coronary artery and its major blood vessels may help to overcome potential difficulties in certain cardiosurgical procedures. A cadaveric study in an unsuspected population provides a basis for understanding the normal variants, which may facilitate determination of the prevalence of anomalies and evaluation of the value of screening for such anomalies. METHODS: The study was carried out on 30 embalmed hearts in the department of anatomy SAIMS. Numbers of ostia, position of the ostia within each aortic sinus with reference to the sinutubular [ST] ridge and the upper margin of cusps were noted. The height of the cusps and the coronary ostia were measured from the bottom of the aortic sinuses [nadir] with the help of a digital vernier caliper. Positions of the ostia were also observed with reference to the commissures. RESULTS: The number of Ostia in the various Aortic sinuses ranges from 1to 3. No openings were found in Right Posterior Aortic Sinus. In majority cases the position of Coronary Ostia is above the Upper margin of cusps (95\%). In 80\% cases the position of Coronary Ostia is below the Sinu-tubular ridge. In 63\% cases ostial openings were centrally located. The Left cusps were found to have greater height as compared to Right cusps. The height of Left coronary ostia was at higher level $(15.65 \mathrm{~mm})$. CONCLUSION: Variant anatomy of the ostia of the coronary artery, its detailed knowledge and awareness of major blood vessels may help to overcome potential difficulties in certain cardiosurgical procedures.
\end{abstract}

KEYWORDS: Coronary Ostium, Aortic Cusp, Aortic Sinus, Commissure.

INTRODUCTION: The word 'coronary' is derived from a Latin word which refers to a crown like arrangement of coronary arteries as they encircle the heart in the atrioventricular sulcus. According to the World Health Organization (WHO), coronary heart diseases constitute the main cause of death in the industrial world. ${ }^{1}$

Coronary_heart_disease is responsible for 1 in 5 deaths in the United States. It is becoming more common in the developing world like India, where cardiovascular disease (CVD) is the leading cause of death. ${ }^{2}$ The deaths due to CVD in India rose from 1.17 million in 1990 and 1.59 million in 2000 to 2.03 million in $2010 .^{3}$ Although relatively a new epidemic in India, it has quickly become a major health issue.4 A detailed normal study of coronary arteries would be of use to cardiologists and interventional radiologist to predefine the abnormalities by invasive and non-invasive studies.

The coronary arteries arise from the aortic sinuses, also called the sinuses of Valsalva. These sinuses are named according to their position as the anterior, left posterior, and right posterior aortic sinuses. The right coronary artery arises from the anterior coronary sinus and the left coronary 


\section{ORIGINAL ARTICLE}

artery from the left posterior aortic sinus. In clinical terminology, the anterior, left posterior and right posterior sinuses are often called the right, left, and non-coronary sinuses, and respectively. ${ }^{5}$

Recently, coronary artery anomalies as a cause of coronary heart disease are gaining consideration in the diagnostic workup. One of the subsets of coronary artery anomalies is the anomalous origin. This subgroup has important clinical manifestations, including sudden death, especially in young athletes. ${ }^{6}$ Some authors have indicated the need to establish diagnostic screening protocols for athletes and other young individuals subjected to extreme exertion. ${ }^{7}$ According to Loukas et al. (2009), it is desirable to determine the incidence of the variations, which are potentially capable of inducing sudden cardiac death, in order to analyze the value of screening. ${ }^{7}$

Variations of coronary vessels especially at the level of origin are frequent. Normally the orifices of coronary arteries are situated at aortic sinuses below the supravalvular ridge. Few systematic studies have described the normal and variant anatomy of coronary artery ostia in an unsuspected population. ${ }^{8,9,10,11}$ Genetic and geographic variations in the coronaries are a known fact. Garg et al. (2000).12 and Harikrishnan et al. (2002).13 have reported the incidence of coronary artery anomalies in angiographic studies for the Indian population.

More detailed knowledge of the human heart and its major blood vessels may help to overcome potential difficulties in certain cardiosurgical procedures, such as aortic valve replacement and reinsertion of coronary arteries.

High degree of association exists between anomalies of the coronary ostia and other congenital cardiovascular defects. Anomalies of the coronary ostia are of greater practical significance than those of coronary arterial distribution. The great importance of coronary catheterization for diagnostic and therapeutic purposes has currently motivated several studies on the anatomic position of coronary ostia.

A cadaveric study in an unsuspected population provides a basis for understanding the normal variants, which may facilitate determination of the prevalence of anomalies and evaluation of the value of screening for such anomalies.[7] Considering the significance of the knowledge of the coronary arterial pattern in cardiac surgeries and keeping in mind the ever evolving and yet unexplored facets of this subject, the present study was undertaken to shed more light on this topic.

MATERIAL AND METHODS: The heart specimens for this study were obtained from the Department of Anatomy, SAIMS Medical College, Indore. The sample size for the study comprised of 30 adult heart specimens collected over a period of 2 years. After opening the thorax, the pericardial cavity was opened, the great vessels were ligated and the specimen of the heart along with great vessels removed from the thoracic cage. Dissections conducted to trace each coronary artery. The ascending aorta was transversally sectioned approximately $2 \mathrm{~cm}$ above the commissures of the aortic leaflets. The aortic root was opened by a vertical incision from the ascending aorta down upto the aortic sinus and into the vestibule of left ventricle. Care was taken that this incision passed through the commissure between non-coronary and the left posterior coronary sinus. The wall of the aorta was flattened to visualize the sinu-aortic ridge, the cusps, number and position of the coronary ostia.

\section{Following observations were made and recorded:}

1. Numbers of ostia were noted within each aortic sinus.

2. The position of the ostia with reference to the sinutubular [ST] ridge and the upper margin of cusps. 


\section{ORIGINAL ARTICLE}

3. The height of the cusps and the coronary ostia were measured from the bottom of the aortic sinuses [nadir] with the help of a digital vernier caliper. (In cases where the ostium was shifted towards one of the commissures, the height of the ostium was not recorded.)

4. Positions of the ostia were also observed with reference to the commissures.

- $\quad$ Commissure I-- placed between Right coronary and Non-coronary sinus.

- Commissure II-- placed between Non coronary and Left coronary sinus

- Commissure III-- placed between Left coronary and Right coronary sinus.

ETHICAL ISSUES: The study was initiated only after the approval given by the Ethical Committee of the institution.

OBSERVATIONS: All the hearts for the present study were grossly normal. Interior of the chambers were opened to see any anomalies. As described in the material and methods the lower part of the ascending aorta, aortic sinuses and the region of aortic vestibule were dissected. The various parameters to be studied were clearly visualized and as planned various metrical and non-metrical features were recorded and photographed.

The following were studied and measured: (i) the position of the coronary ostia inside the aortic sinus; (ii) the position of the coronary ostia from the sinotubular junction, which is a border between the aortic sinus of Valsalva and the ascending aorta; (iii) the position of the coronary ostia inside the corresponding aortic sinus relative to its midline.

The various observations were tabulated as given below:

\begin{tabular}{|c|c|c|c|c|}
\hline \multirow{2}{*}{$\begin{array}{c}\text { No. of } \\
\text { Openings }\end{array}$} & $\begin{array}{c}\text { Anterior (Right) } \\
\text { Aortic Sinus } \\
(\mathbf{N = 3 0 )}\end{array}$ & $\begin{array}{c}\text { Left Posterior } \\
\text { Aortic Sinus } \\
\text { (N= 30) }\end{array}$ \\
\cline { 2 - 5 } & No. & $\mathbf{\%}$ & No. & $\mathbf{\%}$ \\
\hline 0 & 0 & 0 & 00 & 00 \\
\hline 1 & 16 & 53.30 & 28 & 93.33 \\
\hline 2 & 12 & 40.00 & 02 & 06.67 \\
\hline 3 & 02 & 06.67 & 00 & 00 \\
\hline 4 & 00 & 00 & 00 & 00 \\
\hline Total & $\mathbf{3 0}$ & \multicolumn{6}{|c|}{$\mathbf{1 0 0 . 0 0}$} & $\mathbf{3 0}$ & $\mathbf{1 0 0 . 0 0}$ \\
\hline Table I: Showing the number of Coronary \\
Ostia in the various Aortic sinuses \\
\hline
\end{tabular}

\section{It was observed that:}

1. One Ostia was seen in Anterior Aortic Sinus (AAS) in 16 cases (53.3\%) and in 28 cases in Left Posterior Aortic Sinus (93.33\%). (Fig. 1- A).

2. Two openings were seen in AAS in 12 cases (40\%) (Fig.1- B) and in 2 cases in LPAS (6.67\%).

3. Three openings were seen in 2 cases $(6.67 \%)$ in AAS.

4. No ostia was in the Right Posterior Aortic (non-coronary) sinus. (Fig. 1-B). 


\section{ORIGINAL ARTICLE}

\begin{tabular}{|c|c|c|c|c|}
\hline \multirow{2}{*}{ Position } & \multicolumn{2}{|c|}{ Right } & \multicolumn{2}{c|}{ Left } \\
\cline { 2 - 5 } & No. & $\mathbf{\%}$ & No. & \% \\
\hline At & - & - & 1 & 3.33 \\
\hline Above & 28 & 93.33 & 29 & 96.67 \\
\hline Below & 2 & 6.67 & - & - \\
\hline Total & $\mathbf{3 0}$ & $\mathbf{1 0 0}$ & $\mathbf{3 0}$ & $\mathbf{1 0 0}$ \\
\hline $\begin{array}{r}\text { Table II: Showing the position of Coronary Ostia in } \\
\text { relation to the Upper margin of cusps }\end{array}$ \\
\hline
\end{tabular}

\section{It was observed that:}

1. In 28 cases (93.33\%) Right Coronary Ostia were seen above the upper margin of cusps in AAS (Fig. 1-A) and in 29 cases (96.67\%) Left Coronary Ostia were seen above the upper margin of cusps in LPAS. (Fig. 2-A, \& 2-C).

2. In 2 cases (6.67\%) Right Coronary Ostia was seen below the upper margin of cusps in AAS. In none of the cases Left Coronary Ostia was observed below the upper margin of cusps.

3. In 1 case (3.33\%) Left Coronary Ostia was observed at the upper margin of cusps. In none of the cases Right Coronary Ostia was observed at the upper margin of cusps.

\begin{tabular}{|c|c|c|c|c|}
\hline \multirow{2}{*}{ Position } & \multicolumn{2}{|c|}{ Right } & \multicolumn{2}{c|}{ Left } \\
\cline { 2 - 5 } & No. & $\mathbf{\%}$ & No. & \% \\
\hline At the STR & 2 & 6.67 & 8 & 26.67 \\
\hline Above the STR & 1 & 3.33 & 1 & 3.33 \\
\hline Below the STR & 27 & 90.00 & 21 & 70.00 \\
\hline Total & $\mathbf{3 0}$ & $\mathbf{1 0 0}$ & $\mathbf{3 0}$ & $\mathbf{1 0 0}$ \\
\hline Table No. III: Showing the position of Coronary Ostia in \\
relation to Sinu-tubular ridge (STR) \\
\hline
\end{tabular}

\section{It was observed that:}

1. In 2 cases $(6.67 \%)$ opening of Right Coronary Ostia were seen at the Sinu-tubular ridge and in 8 cases (26.67\%) opening of Left Coronary Ostia were seen at the Sinu-tubular ridge. (Fig. 2-B).

2. In 1 case (3.33\%) opening of Right Coronary Ostia was seen above the Sinu-tubular ridge and also in 1 case (3.33\%) opening of Left Coronary Ostia was seen above the Sinu-tubular ridge.

3. In 27 cases $(90.00 \%)$ opening of Right Coronary Ostia were seen below the Sinu-tubular ridge (Fig. 1- A) and in 21 cases (70\%) opening of Left Coronary Ostia were seen below the Sinutubular ridge. (Fig. 2-A \& C).

\begin{tabular}{|c|c|c|c|c|}
\hline \multirow{2}{*}{ Position } & \multicolumn{2}{|c|}{ Right } & \multicolumn{2}{c|}{ Left } \\
\cline { 2 - 5 } & No. & $\mathbf{\%}$ & No. & $\mathbf{\%}$ \\
\hline Central & 18 & 60.00 & 20 & 66.67 \\
\hline Near Commissure -I & 12 & 40.00 & - & - \\
\hline Near Commissure -II & - & - & 8 & 26.67 \\
\hline Near Commissure -III & - & - & 2 & 6.67 \\
\hline Total & $\mathbf{3 0}$ & $\mathbf{1 0 0}$ & $\mathbf{3 0}$ & $\mathbf{1 0 0}$ \\
\hline $\begin{array}{r}\text { Table IV: Showing the position of Coronary } \\
\text { Ostia in relation to Commissures }\end{array}$ \\
\hline
\end{tabular}




\section{ORIGINAL ARTICLE}

\section{It was observed that:}

1. The position of Right Coronary Ostia was central (Fig. 1-A) in 18 cases (60\%) and in Left Coronary Ostia in 20 cases (66.67\%). (Fig. 1-B).

2. The position of Right Coronary Ostia was shifted towards commissure I in 12cases (40\%).

3. The position of Left Coronary Ostia was shifted towards commissure II in 8cases (26.67\%). (Fig. 1-A).

4. The position of Left Coronary Ostia was shifted towards commissure III in 2cases (6.67\%).

(Fig. 2-B).

\begin{tabular}{|c|c|c|c|c|c|}
\hline \multirow{2}{*}{ Group } & \multirow{2}{*}{$\begin{array}{l}\text { Height of } \\
\text { Cusp }\end{array}$} & \multicolumn{2}{|c|}{ Right } & \multicolumn{2}{|c|}{ Left } \\
\hline & & No. & $\%$ & No. & $\%$ \\
\hline I & $0-4.99$ & 1 & 3.33 & - & - \\
\hline II & $5.00-9.99$ & 9 & 30.00 & 10 & 33.33 \\
\hline III & $10.00-14.99$ & 20 & 66.67 & 18 & 60.00 \\
\hline IV & $>15.00$ & - & - & 02 & 6.67 \\
\hline & Total & 30 & 100.00 & 30 & 100.00 \\
\hline & Mean & \multicolumn{2}{|c|}{10.71} & \multicolumn{2}{|c|}{11.35} \\
\hline
\end{tabular}

Height of the cusp from the nadir to nodule (in $\mathrm{mm}$ ) was divided into 4 groups.

\section{It was observed that:}

1. Group I (0-4.99 mm): 1 case (3.33\%) in Right Anterior Aortic Cusps.

2. Group II (5-9.99 mm): 9 cases (30\%) in Right Anterior Aortic Cusps and in 10 cases (33.33\%) In Left Posterior Aortic Cusps.

3. Group III (10 -14.99 mm): 20 cases (66.67\%) in Right Anterior Aortic Cusps and in 18 cases (60\%) In Left Posterior Aortic Cusps.

4. Group IV (above $15 \mathrm{~mm}$ ): 2 cases (6.67\%) in Left Posterior Aortic Cusps.

5. Mean of Height of Right Anterior Aortic Cusps - $10.71 \mathrm{~mm}$.

6. Mean of Height of Left Posterior Aortic Cusps - 11.35 mm.

\begin{tabular}{|c|c|c|c|c|c|}
\hline \multirow{2}{*}{ Group } & Height of & \multicolumn{2}{|c|}{ Right } & \multicolumn{2}{c|}{ Left } \\
\cline { 3 - 6 } & Ostia & No. & \% & No. & $\%$ \\
\hline I & $0-4.99$ & 01 & 3.33 & - & - \\
\hline II & $5.00-9.99$ & - & - & - & - \\
\hline III & $10.00-14.99$ & 17 & 56.67 & 12 & 40.00 \\
\hline IV & $15.00-19.99$ & 10 & 33.33 & 15 & 50.00 \\
\hline V & $>20.00$ & 02 & 6.67 & 03 & 10.00 \\
\hline \multicolumn{7}{|c|}{ Total } & 30 & 100.00 & 30 & 100.00 \\
\hline \multicolumn{7}{|c|}{ Table VI: Showing the Height of Coronary Ostia } \\
in five groups from nadir in mm \\
\hline
\end{tabular}

Height of the coronary ostia from nadir (in mm) was divided into 5 groups. 


\section{ORIGINAL ARTICLE}

\section{It was observed that:}

1. Group I (0-4.99 mm): In 1 case (3.33\%) in Right Anterior Aortic Sinus.

2. Group II (5- $9.99 \mathrm{~mm}):-$ Nil.

3. Group III (10 -14.99 mm): In 17 cases (56.67\%) in Right Anterior Aortic Sinus and in 12 cases (40\%) in Left Posterior Aortic Sinus.

4. Group IV (15 -19.99 mm): In 10 cases (33.33\%) in Right Anterior Aortic Sinus and in 15 cases (50\%) in Left Posterior Aortic Sinus.

5. Group V (more than $20 \mathrm{~mm}$ ): In only in 2 cases $(6.67 \%)$ in Right Anterior Aortic Sinus and in 3 cases (10\%) in Left Posterior Aortic Sinus.

6. Mean of Height of Right Coronary Ostia from nadir-14.82 mm.

7. Mean of Height of Left Coronary Ostia from nadir-15.65 mm.

8. The height of the ostium was not recorded in 1 case $(3.33 \%)$ because right ostium was at the commissure.

DISCUSSION: Knowledge of and the ability to recognize and identify the variations of sites of origin of coronary arteries will help to overcome potential difficulties in cardiosurgical procedures as reinsertion of coronary arteries. Anomalous origins of the coronary arteries often cause heart disease in young patients and increase the risk of sudden death during physical exertion. Several studies have been conducted by various authors on coronary ostia and their variations have been reported as described in the literature.

Standring et al.(2008). ${ }^{14}$ described that the first and highest branch of the proximal segment of right coronary artery, the conus artery arises in 36\% of the cases from a separate ostium (third coronary artery), in the right aortic sinus of Valsalva. Garg et al. (2000).12 reported that the most frequent coronary artery variations were observed in the RCA (62\%) and the left circumflex branch (27\%), while Topaz et al (1992). ${ }^{15}$ observed $48.71 \%$ of variations in the RCA and $35.89 \%$ in the left circumflex branch. Fazliogullari et al. (2010).16 determined that the most frequent variation (64\%) was the conus branch of the RCA, which originates from the aortic sinus.

While reviewing the literature by Joshi et al. (2010). ${ }^{5}$ description of the right coronary sinus having multiple openings was found. The extra openings were minute and varied in number from one to three. These openings are of the first branch of the right coronary artery, the infundibular branch. In approximately $8 \%$ of hearts, the openings were three or more in number. In such cases, one of the extra ostia may be that of the SA nodal artery. In 50\% of cases, the SA nodal artery arises as a branch of the initial part of the right coronary artery.

The work of Schlesinger et al. (1949) and James (1961) as reported by Joshi et al. (2010). ${ }^{5}$ have described the origin of the SA nodal artery directly from the aortic sinuses in some instances. Standring et al. (2008). ${ }^{14}$ have reported the incidence of extra openings in the right aortic sinus in $36 \%$ of individuals. Sahni and Jit (1989). ${ }^{8}$ reported extra openings in $34.8 \%$ of male hearts and $27.8 \%$ of female hearts. The work of Wolloscheck et al. (2001) as reported by Joshi et al. (2010). ${ }^{5}$ found extra ostia in $65 \%$ of cases in an anatomic and transthoracic echocardiographic study. Gajbe et al. (2010). ${ }^{1}$ reports the incidence of third coronary artery in $16 \%$. In $6 \%$ two ostia in the anterior aortic sinus, one for the right coronary artery and one for the right conus artery, respectively.

In the present study, One Ostia was seen in Anterior Aortic Sinus (AAS) in 53.3\% and in Left Posterior Aortic Sinus (LPAS) in $93.33 \%$. Two openings were seen in AAS in $40 \%$ and in LPAS 6.67\%.Three openings were seen in $6.67 \%$ in AAS. 


\section{ORIGINAL ARTICLE}

(Table I, Fig. 1-A \& B). Most of the reports in the literature confirm our findings that the AAS (Right coronary sinus) may have the multiple openings (Including third coronary artery) as compared to the Left coronary ostia variations. The studies reviewed are representative of the various parts of the world and do not show any trend towards gender, age, race, or regional preponderance.

Joshi et al. (2010). ${ }^{5}$ reported that the majority of the ostia were at or above the level of the upper margin of the cusps (84\%). This observation suggest that the positioning of the ostium within the sinus, rather than at or above the ridge, is functionally advantageous. In the present study it was observed that the position of Coronary Ostia in relation to the upper margin of cusps (Table II, Fig. 1A, 2- A \& C) were 93.33\% Right Coronary Ostia were seen above the upper margin of cusps in AAS and in $96.67 \%$ Left Coronary Ostia were seen above the upper margin of cusps in LPAS. Only in $6.67 \%$ Right Coronary Ostia was seen below the upper margin of cusps in AAS. In none of the cases Left Coronary Ostia was observed below the upper margin of cusps.

Only in 3.33\% Left Coronary Ostia was observed at the upper margin of cusps. In none of the cases Right Coronary Ostia was observed to be at the upper margin of cusps. Joshi et al.(2010). ${ }^{5}$ have also observed a very high incidence (84\%) of ostia at or above the level of upper margin of cusps and in $7 \%$ ostial openings were below the upper margin of cusps. Not many workers have tried to study the relationship of ostia to the upper margin of cusps.

The right coronary artery arises from anterior aortic sinus below the supravalvular ridge. In present study (Table III, Fig. 1-A \& B) in 90\% right coronary ostia were present below the sinutubular ridge. We also found that right coronary ostium was present at the sinutubular ridge in only $6.67 \%$ cases. Turner and Navratnam (1996). ${ }^{10}$ found that 62 of the 74 main coronary ostia lay either at or immediately below the sinutubular ridge. Joshi S et al. (2010). ${ }^{5}$ reported that the majority of the ostia lay below the sinutubular ridge (89\%) In a study by Vlodaver et al. (1972) as reported by Bhimali et al. (2005). ${ }^{17}$ the author observed in $56 \%$ of the cases the orifice of the coronary arteries were situated in aortic sinus below the supravalvular ridge and in $8 \%$ of the cases the origin of right coronary artery occurred above the supravalular ridge. Pejkovic et al. (2008). ${ }^{11}$ have reported a very high incidence of ostia at or above the level of the sinutubular junction ( $82 \%$ left and $90 \%$ right).

Bhimalli et al. (2005). ${ }^{17}$ determined that $90 \%$ of the coronary ostia of right coronary artery were below the supra valvar ridge and $80 \%$ of the ostia of the left coronary were below the supravalvar ridge. In current study the left coronary artery ostium was situated in the left posterior aortic sinus and in $70 \%$ of the specimens the ostium was present below the sinutubular ridge, and in $26.67 \%$ of the cases it was situated at the sinutubular ridge. In $3.33 \%$ cases both the right and left ostia were above sinutubular ridge. The incidence of the coronary ostia in relation to the sinutubular ridge corroborates with study of the authors reviewed except Pejkovic et al. (2008). ${ }^{11}$ who have reported a very high incidence of coronary ostia at or above the level of the sinutubular junction (82\% left and $90 \%$ right).

The location and level of the ostium is very important in the successful performance of coronary angiogram. Muriago et al. (1997). ${ }^{18}$ added that the more central location of the left coronary ostium is justified, because, after its origin, the left coronary artery heads to the space between the pulmonary trunk and the left auricle, branching immediately after that. Cavalcanti et al. (2003).19 proposed that the left coronary ostium was located in the central region of the corresponding aortic sinus, while the right coronary ostium was displaced to the right in the respective aortic sinus. 


\section{ORIGINAL ARTICLE}

Similar results have also been reported by Scholz et al (1988) and Maron et al (1997) as described by Cavalcanti et al. (2003).19 when studying cardiac mass, valvular circumferences, and ventricular thickness. Joshi et al.(2010)..$^{5}$ documented that right coronary ostium tended to deviate more often towards Commissure I. and the left coronary ostium was located in the central region of the corresponding aortic sinus. Similar results have also been reported by Turner and Navratnam (1996). ${ }^{10}$ In present study the position of Coronary Ostia in relation to Commissures was observed [Table IV, Fig. 1-A, 2-B].The position of Right Coronary Ostia was central in 60\% and Left Coronary Ostia in 66.67\%. The position of Right Coronary Ostia was shifted towards commissure I in 40\%. The position of Left Coronary Ostia was shifted towards commissure II in $26.67 \%$ and towards commissure III in $6.67 \%$.

In the present study height of Cusps was measured from nadir to nodule [Table V]. Joshi et al. (2010). ${ }^{5}$ reported that the height of Left posterior aortic cusp was $11.6 \mathrm{~mm}$ and that of Right anterior aortic cusp was $11.8 \mathrm{~mm}$. whereas in the present series the height of Left posterior aortic cusp was $11.35 \mathrm{~mm}$ and that of Right anterior aortic cusp was $10.71 \mathrm{~mm}$. Thus in the present study the Left cusps was found to have greater height as compared to Right cusps. This finding in variance to that reported by Joshi et al. (2010). ${ }^{5}$

In the present study height of coronary ostia was measured from nadir [Table VI]. Cavalcanti et al. (2003). ${ }^{19}$ mentioned that mean height of right coronary ostia was $13.2+/-2.64 \mathrm{~mm}$. and that of Left coronary ostia was $12.6+/-2.61 \mathrm{~mm}$. Joshi et al. (2010). ${ }^{5}$ reported that the height of Right coronary ostia was $14.08 \mathrm{~mm}$ and that of Left coronary ostia was $13.3 \mathrm{~mm}$. hence the height of Right coronary ostia was at a higher level as reported by Cavalcanti et al. (2003). ${ }^{19}$ and Joshi et al. (2010). ${ }^{5}$ In the present series the height of Left coronary ostia was at higher level $(15.65 \mathrm{~mm})$. Some of the variations that have been observed between the present findings and that of other workers in the field as reviewed in the literature may be correlated with size and weight of the heart and the embryonic development. In the present work no openings were found in pulmonary artery or the non-coronary sinus. Bhimali et al. (2006).17 and Joshi et al. (2010). ${ }^{5}$ reported similar findings.
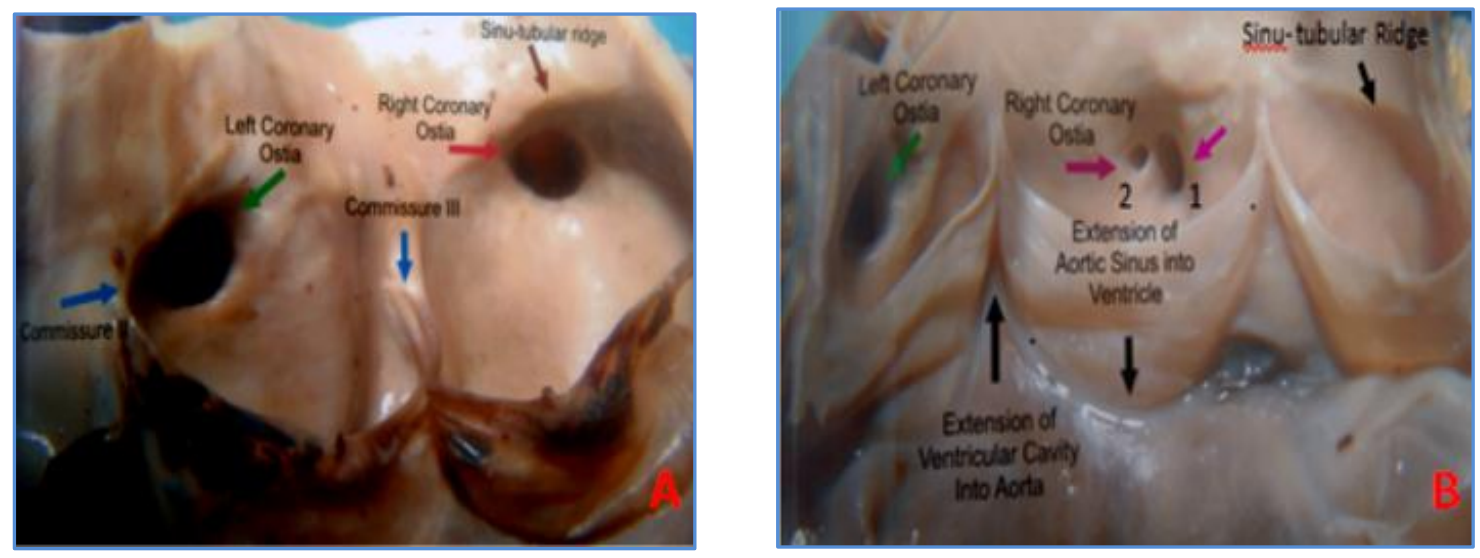

Fig. 1: Showing coronary ostia, its relation to sinu- tubular ridge, to upper margin of cusp \& to the commissure.

Fig. 1 A: Showing large single left coronary ostia shifted towards commissure II \& it is below sinutubular ridge. Right coronary ostia central in location \& just below sinu-tubular ridge.

B: Showing two coronary ostia in anterior aortic sinus below sinu- tubular ridge. 


\section{ORIGINAL ARTICLE}
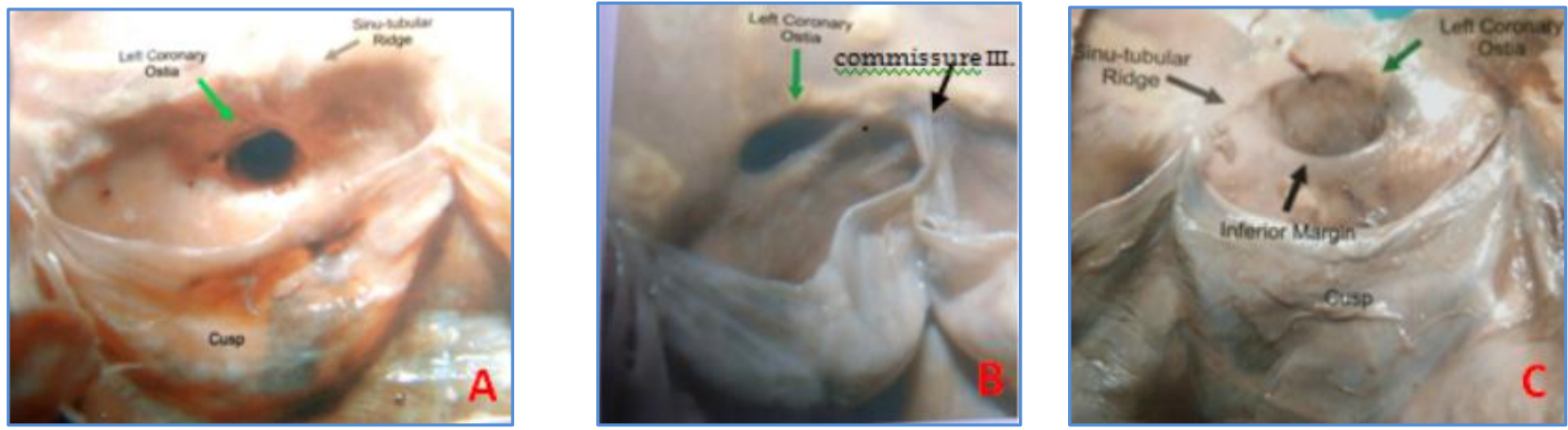

Fig 2: Showing coronary ostia, its relation to sinu-tubular ridge, to upper margin of cusp \& to the commissure.

Fig. 2: A: Showing large central circular left coronary ostia below sinu-tubular ridge\& above the cusp.

B: Showing left coronary ostia at sinu-tubular ridge shifted towards commissure III.

C: Showing large left coronary ostia just below sinu-tubular ridge $\&$ above the cusps.

Inferiors Margin of the ostia is very prominent.

CONCLUSION: The present study describes the normal and variant anatomy of the ostia of the coronary arteries in adult cadavers of Indian origin. Knowledge of and the ability to identify the variation of sites of origin of the coronary arteries in relation to the aorta which will help in coronary angiography and other cardiosurgical procedures, such as aortic valve replacement and coronary reinsertion. The present findings reemphasize the value of performing a preliminary aortic root injection of the dye to locate the exact number of orifices of coronary arteries to avoid fatal outcome that may follow coronary angiography.

\section{REFERENCES:}

1. Gajbe U l, Gosavi S , Meshram S , Gajbhiye V M. The Anomalous origin of multiple coronary ostia and their clinical significance. Journal of Clinical and Diagnostic Research [serial online] 2010 February [cited: 2010 February 1]; 3:2129-2133.

2. Mukherjee AK. (1995). "Prediction of coronary heart disease using risk factor categories". J Indian Med Assoc 93 (8).

3. Ghaffar A, Reddy KS and Singhi M (2004). "Burden of non-communicable diseases in South Asia" (PDF). BMJ 328 (7443): 807-810.

4. Gupta R. (2007). "Escalating Coronary Heart Disease and Risk Factors in South Asians" (PDF). Indian Heart Journal: 214-17.

5. Joshi SD, Joshi SS and Athavale SA. Origins of the Coronary Arteries and Their Significance. Clinics (Sao Paulo). 2010 January; 65(1): 79-84.

6. Basso C, Maron BJ, Corrado D, Thiene G. Clinical profile of congenital coronary anomalies with origin from the wrong aortic sinus leading to sudden death in young competitive athletes. J Am Coll Cardiol. 2000; 35:1493-501.

7. Loukas Marios, $1^{*}$ Groat Christopher, 1 Khangura Rajkamal, 1 Deyzi Gueorgueva owens ,1AND Anderson Robert H. 2. The Normal and Abnormal Anatomy of the Coronary Arteries. Clinical Anatomy 22:114-128 (2009) 


\section{ORIGINAL ARTICLE}

8. Sahni D, Jit I. Origin and size of the coronary arteries in the north-west Indians. Indian Heart J. 1989; 4:221-8.

9. Muriago M, Sheppard MN, Ho SY, Anderson RH. Location of the coronary arterial orifices in the normal heart. Clin Anat. 1997;10:297-302

10. Turner Kevin and Navaratnam Visvan, The position of coronary arterial ostia. Clinical anatomy 9: 376-380 (1996)

11. Pejkovi'c B, Krajnc I, Anderhuber F. Anatomical Variations of Coronary Ostia, Aortocoronary Angles and Angles of Division of the Left Coronary Artery of the Human Heart. The Journal of International Medical Research 2008; 36: 914-922.

12. Garg N, Tiwari A. Primary congenital anomalies of the coronary arteries: a coronary arteriographic study. Int J Cardiol. 2000;74:39-46

13. Harikrishnan S, Jacob SP, Tharakan J, Titus T, Ajith Kumar VK, Bhat A, et al. Congenital coronary anomalies of origin and distribution in adults: a coronary arteriographic study. Indian Heart J. 2002; 54:271-5.

14. Standring S, Borley NR, Collins P, Crossman AR, Gatzoulis MA, Healy JC et al. In Gray's Anatomy: The anatomical basis of clinical practice. 40 th Edition. London Churchill Livingstone, $2008 \mathrm{Sec} 7$, pages 968-981.

15. Topaz O, DiSciascio G, Cowley MJ, Soffer A, Lanter P, Goudreau E, et al. Absent left main coronary-artery-angiographic findings in 83 patients with separate ostia of the left anterior descending and circumflex arteries at the left aortic sinus. Am Heart J. 1991; 122:447-52.

16. Fazliogullari Z, Karabulut A K, Unver Dogan N, Uysal I I, Coronary artery variations and median artery in Turkish cadaver hearts, Singapore Med J 2010; 51(10) : 775.

17. Bhimalli S, Hukkeri VB, Potturi BR. A study of Variation Anomalies of Coronary Artery in Cadaveric Human Hearts. Journal of the Anatomical Society of India Vol. 54, No. 1 (2005-012005-03).

18. Muriago M, Sheppard MN, Ho SY, Anderson RH. Location of the coronary arterial orifices in the normal heart. Clin Anat. 1997;10:297-302.

19. Cavalcanti Jennecy Sales; Natália Corrêa Vieira de Melo; Renata Simões de Vasconcelos. Morphometric and topographic study of coronary ostia, Arq. Bras. Cardiol. vol.81 no.4 São Paulo Oct. 2003. 


\section{ORIGINAL ARTICLE}

\section{AUTHORS:}

1. Rupa Chhaparwal

2. S. S. Joshi

3. S. D. Joshi

\section{PARTICULARS OF CONTRIBUTORS:}

1. Assistant Professor, Department of Anatomy, Sri Aurobindo Medical College, and Post Graduate Institute Indore.

2. Professor and HOD, Department of Anatomy, Sri Aurobindo Medical College, and Post Graduate Institute Indore.

\section{FINANCIAL OR OTHER} COMPETING INTERESTS: None
3. Professor and Dean, Department of Anatomy, Sri Aurobindo Medical College, and Post Graduate Institute Indore.

\section{NAME ADDRESS EMAIL ID OF THE} CORRESPONDING AUTHOR:

Dr. Rupa Chhaparwal, T. 102, Shalimar Town Ship, Behind Satya Sai, AB Road, Indore-452001,

Madhya Pradesh, India.

E-mail: cdrupa29@gmail.com

Date of Submission: 01/10/2015.

Date of Peer Review: 02/10/2015.

Date of Acceptance: 13/10/2015.

Date of Publishing: 20/10/2015. 